\title{
ADSORPTION OF INORGANIC AS(III) FROM AQUEOUS SOLUTIONS BY IRON-MANGANESE OXIDE
}

\author{
Rashmi Koju, ${ }^{* * *}$ Agni Dhakal, ${ }^{*}$ Sushila Gwachha, ${ }^{* * * *}$ Dev Raj Joshi, ${ }^{* * *}$ Tista Prasai Joshi" and Sujen \\ Man Shrestha* \\ *Environment and Climate Study Laboratory, Faculty of Science, Nepal Academy of Science and Technology (NAST), \\ Khumaltar, Lalitpur, Nepal. \\ ${ }^{* *}$ Research Center for Eco-Environment Science (RCEES), Chinese Academy of Sciences (CAS), Beijing, China. \\ ***Central Department of Microbiology, Tribhuvan University, Kathmandu, Nepal. \\ ****Department of Environment Science, Khwopa College (affiliated to Tribhuvan University), Bhaktapur, Nepal.
}

\begin{abstract}
Arsenic contamination in water is well noted public health issue in Nepal and elsewhere. Adsorbents are important chemical means to purify the arsenic contaminated water. In this study the adsorption of As(III) on iron manganese oxide has been investigated as a function of different parameters. Herein, two iron based adsorbents, ironmanganese oxide-1 (Fe-Mn oxide-1) and iron-manganese oxide-2 (Fe-Mn oxide-2) were prepared by oxidation and coprecipitation methods. Adsorbents were characterized by powder X-ray diffraction (XRD) and scanning electron microscope (SEM). Within 4 hours of reaction time, 90\% of the arsenic was removed by both Fe-Mn oxides and removal efficiency of the Fe-Mn oxide-1 was obtained higher than that of Fe-Mn oxide-2. Pseudo-second order model was well fitted to describe adsorption kinetic $\left(\mathrm{R}^{2}=0.99\right)$ for both adsorbents. Removal efficiency of the absorbents decreased with increase in the $\mathrm{pH}$ value and increased with increase in the concentration of adsorbent in the suspension. Based on the result, the synthesized Fe-Mn oxides have significant potential applications in the inorganic arsenic treatment in the water.
\end{abstract}

Keywords: Arsenite; Adsorption; Amorphous; Fe-Mn oxide.

\section{INTRODUCTION}

Arsenic in water has become a global threat as pollutants in drinking water and ground water due to its toxic, carcinogenic and omnipresent nature. Arsenic is mobilized into water bodies both by natural processes and anthropogenic activities. Arsenic exists two predominant inorganic species; arsenite $[\mathrm{As}(\mathrm{III})]$ under reducing condition and arsenate $[\mathrm{As}(\mathrm{V})]$ under oxidizing condition in a water environmen ${ }^{[1}$. Long-term uptake of arsenic contaminated water even at low level, can cause arsenicosis, a disease leading to serious health effects like respiratory, pulmonary, cardiovascular, hematological, gastrointestinal, hepatic, dermal, renal, neurological, mutagenic, immunologic, diabetes mellitus, and so $\mathrm{on}^{2}$. As an effect of arsenic, WHO and USEPA have reinforced guideline value of $10-\mu \mathrm{g} / \mathrm{L}^{3}$. Arsenic poisoning episode in natural ground water has been reported from several countries like Taiwan, West Bengal-India, Chile, Argentina, Mexico, Hungary, Canada, Vitenam, China, USA, Sri Lanka etc ${ }^{4,5,6}$.

A variety of treatment technologies have been reported for the removal of arsenic from arsenic contaminated water such as precipitation, co-precipitation, ultrafiltration, ion exchange and reverse osmosis ${ }^{3}$. Among all these technologies, adsorption method is found efficient, simple and economical ${ }^{7}$. Different types of adsorbents; goethite ${ }^{8}$, low cost ferruginous manganese ore, polyaluminium granulate ${ }^{9}$, zeoliticimidazolate frameworks ${ }^{10,11}$, multi-wall carbon nanotubes (MWCNTs) ${ }^{12}$, ferrihydrite ${ }^{13}$, copper oxide nanoparticles ${ }^{5}$, ferrihydrite ${ }^{14}$, granular schwertmannite ${ }^{15}$ and soon have been applied for the adsorption of arsenic. Mobility and adsorption behavior of arsenic is dependent on its oxidation state and $\mathrm{As}(\mathrm{V})$ is found to be easily removed than As(III). So, conversion of As (III) to As (V) and simultaneous adsorption of $\mathrm{As}(\mathrm{V})$ is required for the complete removal of arsenic from contaminated water. The objective of this study was to prepare and characterize Fe-Mn oxide adsorbents which can be applied to arsenic (III) removal from water. The prepared adsorbents were characterized by XRD and SEM. Efficiency of arsenic adsorption on the adsorbent was assessed by a series of batch experiments such as adsorption kinetics, effect of $\mathrm{pH}$ and adsorbent dosages.

\section{EXPERIMENTAL SECTION}

\subsection{Materials}

All the chemicals used throughout this study were of analytical grade reagent. Arsenite (As(III)) stock solutions were prepared by dissolving sodium arsenite $\left(\mathrm{NaAsO}_{2}\right)$ (LOBA CHEMIE PVT.LTD, India) in deionized water. Working solution of As (III) were freshly prepared by diluting the As(III) stock solution with deionized water.

\subsection{Synthesis of adsorbent}

Two different iron-manganese oxides (Fe-Mn oxide-1 and Fe-Mn oxide-2) were synthesized by oxidation and coprecipitation methods followed the procedure reported with slight modifications ${ }^{16}$.

\section{Fe-Mn oxide-1 and Fe-Mn Oxide-2}

Solution 1 was prepared by dissolving Potassium permanganate $\left(\mathrm{KMnO}_{4}, 0.015 \mathrm{M}\right)$ in $200 \mathrm{~mL}$ of deionized water. For Fe-Mn oxide-1, solution 2 was prepared by dissolving ferric chloride hexahydrate $\left(\mathrm{FeCl}_{3} .6 \mathrm{H}_{2} \mathrm{O}, 0.045\right.$ $\mathrm{M})$ in $200 \mathrm{~mL}$ of deionized water. For Fe-Mn oxide-2, the solution 2 was prepared by dissolving ferrous sulphate 
heptahydrate $\left(\mathrm{FeSO}_{4} .7 \mathrm{H}_{2} \mathrm{O}, 0.045 \mathrm{M}\right)$ in $200 \mathrm{~mL}$ of deionized water. Under the magnetic stirring, solution 1 and respective solution 2 for Fe-Mn oxide- 1 and Fe-Mn oxide-2, separately were mixed and $5 \mathrm{M} \mathrm{NaOH}$ solutions were added to make the solution $\mathrm{pH}$ in the range between 7.0 and 8.0. Then formed suspension was stirred for 1 hour and aged at room temperature for 24 hours and repeatedly washed with deionized water. The suspension was filtered and finally dried at $105{ }^{\circ} \mathrm{C}$ for 4 hours in an oven. The dried material was crushed with a mortar and pestle into fine powders, then sieved to obtain a particle size less than $100-\mu \mathrm{m}$ and stored in vacuum desiccators until further use.

\subsection{Structural characterization}

The basic properties such as degree of crystallinity and the morphology of the adsorbents were examined using powder X-ray diffraction studies (XRD) and Scanning electron microscopy (SEM). Powdered X-Ray Diffract meter, X'Pert 3040-PRO (PAN analytical Co.) with copper as anode material and $0.5 \mathrm{~K} \alpha 1 / \mathrm{K} \alpha 2$ radiation was used. Powdered adsorbents were dried to constant weight and ground. Data were collected at $40 \mathrm{Kev}$ and $40 \mathrm{~mA}$ in Gonio scan axis between $10^{\circ}$ and $90^{\circ} 2 \theta$ in $0.026^{\circ}$ steps. The surface morphology of the adsorbents were observed using Scanning electron microscopy (SEM) (Hitachi S$3500 \mathrm{~N}$, Japan).

\subsection{Adsorption Experiments}

\subsubsection{Adsorption kinetics}

Definite volume of the arsenite stock solution was added to definite volume of deionized water to make a definite concentration of the arsenite in which ionic strength was maintained by the addition of $0.001 \mathrm{M}$ sodium nitrate $\left(\mathrm{NaNO}_{3}\right) \cdot \mathrm{pH}$ of the solution was adjusted to 7.0 by the addition of $0.1 \mathrm{M} \mathrm{HCl}$ and $0.1 \mathrm{M} \mathrm{NaOH}$. Prepared Fe-Mn oxides were added to obtain $0.2 \mathrm{~g} / \mathrm{L}$ suspension. The suspension was mixed in the shaker with speed of 150 rpm for 24 hours at $25{ }^{\circ} \mathrm{C}$. Approximately, $1.5 \mathrm{~mL}$ aliquots from the suspension at the intervals of $0.5,1.0$, 2.0, 4.0, and 24 hours of reaction were taken.

The adsorption capacity of arsenite $\left(\mathrm{q}_{\mathrm{e}}, \mathrm{mg} / \mathrm{g}\right)$ was calculated using the following equations:

$\mathrm{q}_{\mathrm{e}}=\frac{\left(\mathrm{C}_{0}-\mathrm{C}_{\mathrm{e}}\right) \mathrm{V}}{\mathrm{m}}$

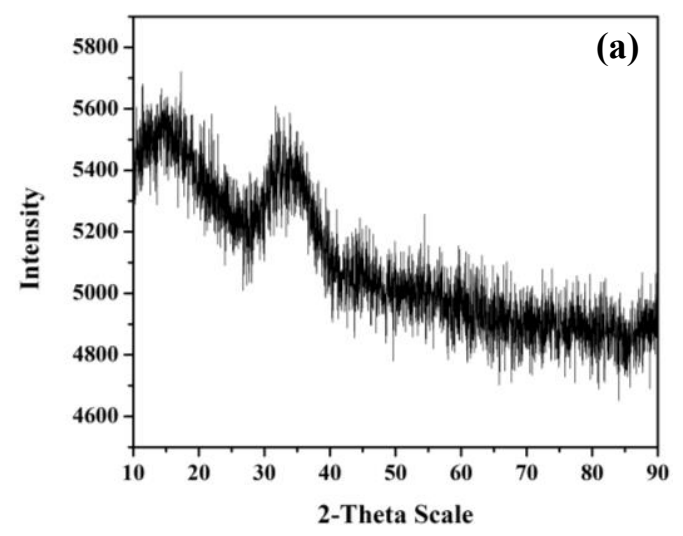

Where, $\mathrm{C}_{0}$ and $\mathrm{C}_{\mathrm{e}}$ are the initial and the remaining concentrations of arsenite solution $(\mathrm{mg} / \mathrm{L}), \mathrm{V}$ is the initial solution volume $(\mathrm{L})$, and $\mathrm{m}$ is the adsorbent weight $(\mathrm{g})$.

The removal rate (\%) was calculated according to eq. (2):

Removal \% $=\frac{\mathrm{C}_{0}-\mathrm{C}_{\mathrm{e}}}{\mathrm{C}_{0}} \times 100$

Where, $\mathrm{C}_{0}$ and $\mathrm{C}_{\mathrm{e}}$ are the initial solution and remaining concentrations of arsenite solution ( $\mathrm{mg} / \mathrm{L})$, respectively.

\subsubsection{Effect of $\mathrm{pH}$}

To find out the effect of $\mathrm{pH}$, solutions containing defined concentration of arsenite were prepared to form solutions with 4.0, 5.0, 6.0, 7.0, 8.0 and $9.0 \mathrm{pH}$ values throughout the experiment by adding $0.1 \mathrm{M} \mathrm{HCl}$ or $0.1 \mathrm{M} \mathrm{NaOH}$. Prepared Fe-Mn oxides were added to obtain $0.2 \mathrm{~g} / \mathrm{L}$ suspension. The suspension was mixed in the shaker with speed of $150 \mathrm{rpm}$ for 24 hours at $25{ }^{\circ} \mathrm{C}$. $1.5 \mathrm{~mL}$ aliquots were taken after 24 hours of reaction time.

\subsubsection{Effect of adsorbent dose}

For observing the effect of concentration of adsorbents, in the solutions containing definite amount of arsenite, different amount of adsorbents were added to make suspensions $0.05 \mathrm{~g} / \mathrm{L}, 0.1 \mathrm{~g} / \mathrm{L}, 0.15 \mathrm{~g} / \mathrm{L}$ and $0.2 \mathrm{~g} / \mathrm{L}$ and $\mathrm{pH}$ was adjusted to 7.0 by the addition of $0.1 \mathrm{M} \mathrm{HCl}$ and $0.1 \mathrm{M} \mathrm{NaOH}$. The suspensions were mixed in the shaker with speed of $150 \mathrm{rpm}$ for 24 hours at $25{ }^{\circ} \mathrm{C}$. $1.5 \mathrm{~mL}$ aliquots from the each suspension were taken after 24 hours of reaction time.

\subsection{Analysis of arsenic}

After adsorption, samples were filtered through $0.45-\mu \mathrm{m}$ membrane filters for the analysis of arsenic As(III). The concentrations of As(III) were determined by Graphite Tube Atomizer (GTA), 240FSAA (Agilent Technologies).

\section{RESULTS AND DISCUSSION}

\subsection{Characterization of adsorbents}

\subsubsection{XRD}

Crystalline peak was not detected in X-ray powder diffraction pattern (XRD) of both Fe-Mn oxides. This indicates that both oxides exist mainly in amorphous form (Fig 1a and b), which increases the surface area of the adsorbent for the adsorption ${ }^{16}$.

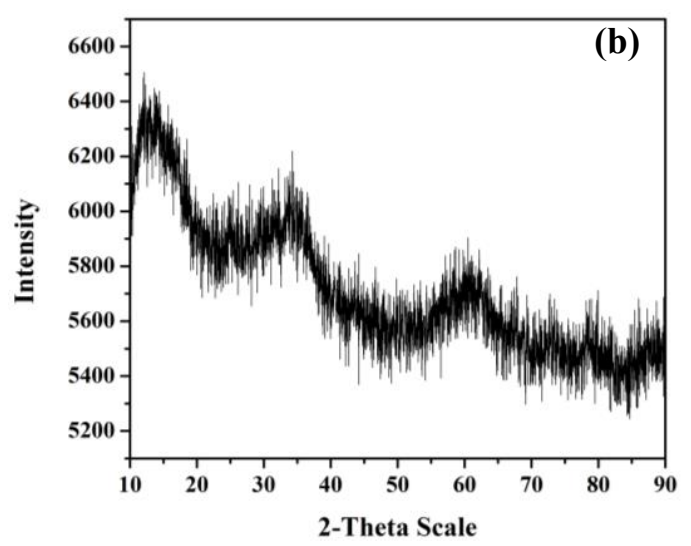

Figure: 1. X-ray diffraction (XRD) pattern of (a) Fe-Mn oxide-1 and (b) Fe-Mn oxide-2. 


\subsubsection{SEM}

Particle shape of the adsorbents studied by Scanning electron microscopy (SEM) showed the presence of many aggregated small particles in both prepared Fe-Mn oxide1 (Fig 2a and b) and Fe-Mn oxide-2 (Fig 3a and b).

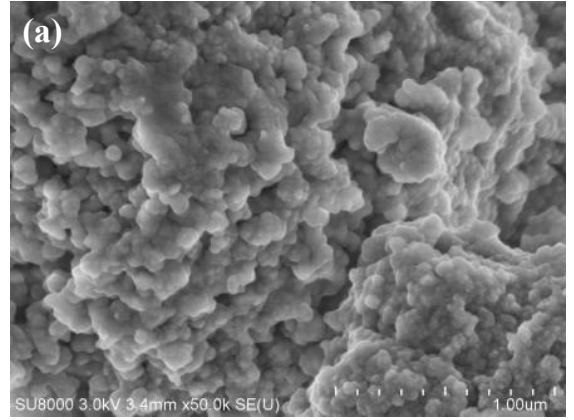

Figur: 2. SEM images of Fe-Mn oxide-1 in different magnification. Scale bars are $1.00-\mu \mathrm{m}$ and $500 \mathrm{~nm}$.

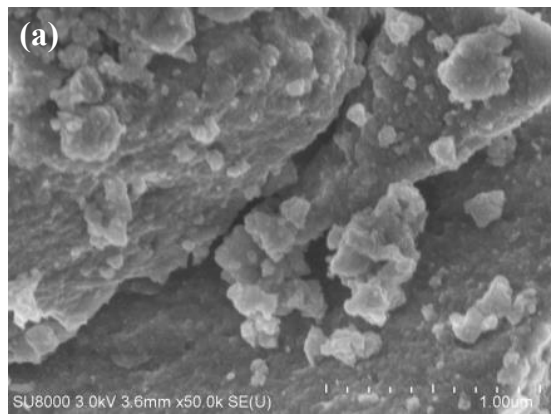

Figure: 3. SEM image of Fe-Mn oxide-2 in different magnification. Scale bars are 1.00- $\mu \mathrm{m}$ and $500 \mathrm{~nm}$.

\subsection{Removal efficiency of adsorbents}

\subsubsection{Adsorption kinetic}

The adsorption kinetics of arsenic (III) onto Fe-Mn oxides were determined through the curves of adsorption capacity as a function of time. Fig 4 a shows that the adsorption of $\mathrm{As}(\mathrm{III})$ on Fe-Mn oxide-1 and Fe-Mn oxide- 2 was fast during the initial stage in 30 minutes and gradually slowed with increasing reaction time. The optimum time to attain the equilibrium was 4 hours. The maximum adsorption capacity of As(III), i.e., $q_{t, \max }$, was observed to be $43.9 \mathrm{mg} / \mathrm{g}$ and $39.45 \mathrm{mg} / \mathrm{g}$ for Fe-Mn oxide- 1 and Fe-Mn oxide- 2 and its removal rate was determined to be $97 \%$ and $94 \%$, respectively (Fig 4b). To gain insight into the adsorption mechanism, Pseudofirst-order and Pseudo-second-order kinetic models were applied to fit experimental data as shown in Table $1^{18}$. Pseudo-second order model was observed fitted well to describe adsorption of $\mathrm{As}$ (III) on both oxides as indicated by higher correlation coefficient values $\left(\mathrm{R}^{2}=0.99\right.$ for both

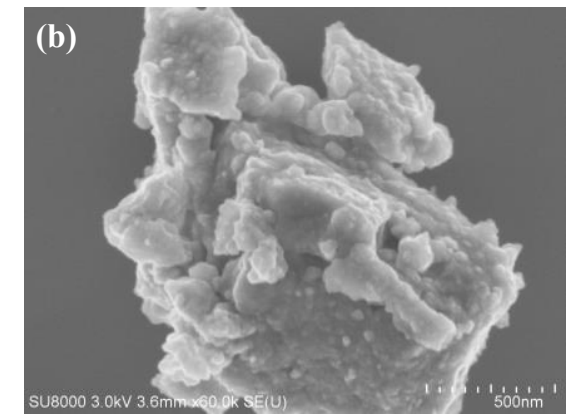

Particles size was found to be smaller in Fe-Mn oxide-1 than in Fe-Mn oxide-2. So, surface of both oxides were $\operatorname{rough}^{17}$.

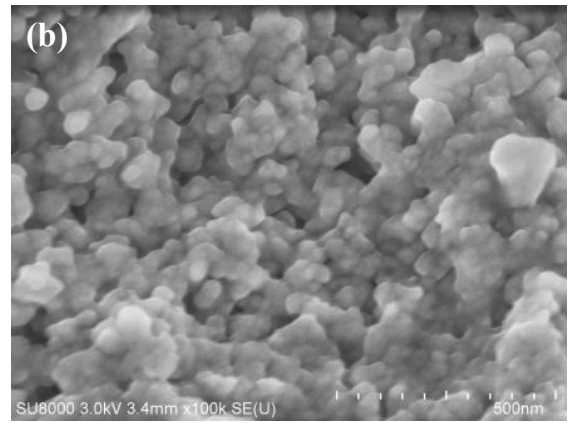

oxides, which indicated that the adsorption process might be chemisorption ${ }^{19,20}$.

The mathematical equations are used to fit experimental data are given as,

Pseudo-first order equation, $\mathrm{q}_{\mathrm{t}}=\mathrm{q}_{\mathrm{e}}\left(1-\mathrm{e}^{-\mathrm{k}_{1} \mathrm{t}}\right)$

Pseudo-second order equation, $\mathrm{q}_{\mathrm{t}}=\frac{\mathrm{q}_{\mathrm{e}}{ }^{2} \mathrm{k}_{2} \mathrm{t}}{1+\mathrm{q}_{\mathrm{e}} \mathrm{k}_{2} \mathrm{t}}$

In eqs. (3) and (4), $\mathrm{q}_{\mathrm{t}}(\mathrm{mg} / \mathrm{g})$ is the adsorption amount at a given time $\mathrm{t}(\mathrm{h})$ and $\mathrm{q}_{\mathrm{e}}(\mathrm{mg} / \mathrm{g})$ is the adsorption equilibrium capacity at the terminal experimental time. In the equations, $K_{1}(1 / \mathrm{h})$ and $K_{2}(g / m g h)$ indicate the adsorption rate constants of the pseudo-first order and pseudo-second-order model.
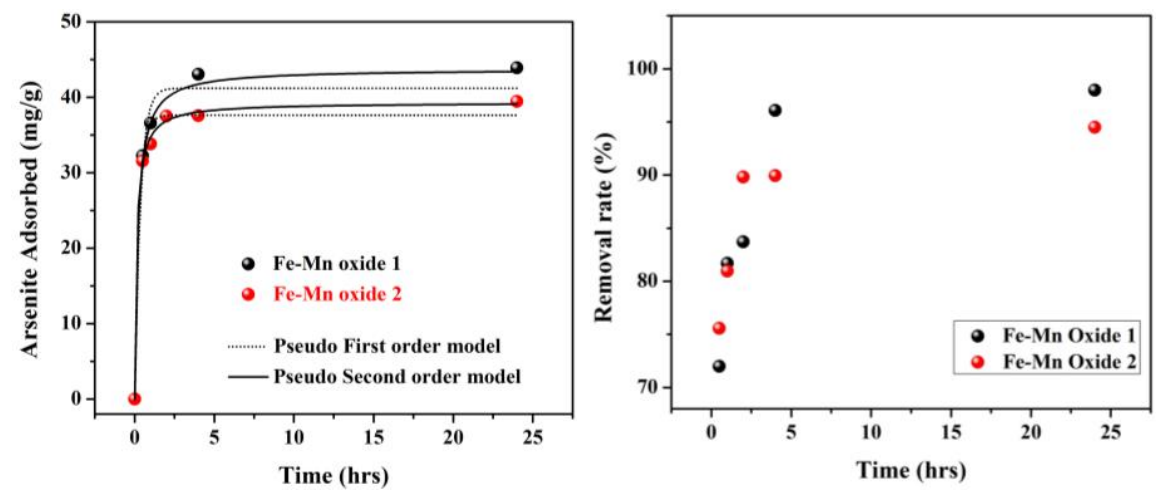

Figure: 4. Adsorption kinetics of As (III) onto Fe-Mn oxide-1 and Fe-Mn oxide-2 at pH 7.0 \pm 0.1 
Table 1. Adsorption kinetic models for the adsorption of As (III) onto adsorbents oxide at pH 7.0.

\begin{tabular}{cccccccc}
\hline Adsorbent & $\begin{array}{c}\text { Initial concentration } \\
\text { of As(III) } \\
\mathrm{mg} / \mathrm{L}\end{array}$ & $Q_{\text {Max }}$ & $K_{1}$ & $\mathrm{R}^{2}$ & $Q_{\text {Max }}$ & $K_{2}$ & $\mathrm{R}^{2}$ \\
& & $\mathrm{mg} / \mathrm{g}$ & $1 / \mathrm{h}$ & & $\mathrm{mg} / \mathrm{g}$ & $\mathrm{g} / \mathrm{mgh}$ \\
\hline Fe-Mn oxide-1 & 8.96 & 41.1 & 2.7 & 0.97 & 43.7 & 0.11 & 0.99 \\
\hline Fe-Mn oxide-2 & 8.35 & 37.6 & 3.3 & 0.98 & 39.2 & 0.19 & 0.99 \\
\hline
\end{tabular}

\subsubsection{Effect of $p H$}

$\mathrm{pH}$ is one of the main influencing factors that affect the adsorptive interaction on the adsorbents. To gain more insight into the adsorption process, the effects of initial $\mathrm{pH}$ on adsorption capacity of arsenic (III) on adsorbents were examined over a wide range of $\mathrm{pH}(4.0-9.0)$, respectively as demonstrated in Fig 5. Adsorption of As (III) was decreased with increase in $\mathrm{pH}$ in both Fe-Mn oxide-1 and Fe-Mn oxide-2 as shown in Fig 5. About $99 \%$ of As (III) was removed by both Fe-Mn oxide- 1 and Fe-Mn oxide- 2 at $\mathrm{pH} 4.0 \pm 0.1$.The removal efficiency was gradually decreased with increase in $\mathrm{pH}$ value and decreases up to about $93 \%$ and $89 \%$ by Fe-Mn oxide-1 and $\mathrm{Fe}-\mathrm{Mn}$ oxide-2, respectively at $\mathrm{pH}$ value $9.0 \pm 0.1$. With increase in $\mathrm{pH}$, positive charge density of the adsorbent decreases and turns into negative charge density resulting in electrostatic force of repulsion ${ }^{21}$. At Lower $\mathrm{pH}$, positive charge increases as a result of protonation of the adsorbent surface and attract negatively charged arsenic anion easily but with increase in the $\mathrm{pH}$ negative charge on adsorbent increases which causes the electrostatic force of repulsion between adsorbent and arsenic anionthus lowering adsorption capacity ${ }^{11,17}$. However, adsorption of As (III) was not measured below $\mathrm{pH} 4$ in this study.

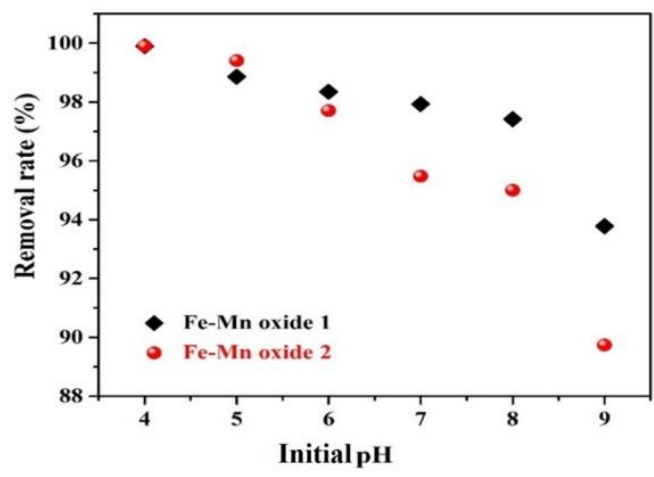

Figure: 5. Effect of $\mathrm{pH}$ on the adsorption of As (III).

\subsubsection{Effect of the dose of adsorbent}

Adsorbent amount is an essential factor for arsenic(III) removal by adsorption process is demonstrated in Fig $6^{5}$. It was found that arsenic removal increased with increasing adsorbent dose up to $0.2 \mathrm{~g} / \mathrm{L}$. With the increase in the concentration of the adsorbent dose from 0.05 to $0.2 \mathrm{~g} / \mathrm{L}$, the removal efficiency of the As (III) increases. The increase in the removal of As(III) may be attributed to increase in the surface area of adsorbent available for mass transfer ${ }^{3}$. Removal efficiency reaches up to $95.97 \%$ and $96.73 \%$ at $0.2 \mathrm{~g} / \mathrm{L}$ dose of Fe-Mn oxide- 1 and Fe-Mn oxide- 2 respectively.

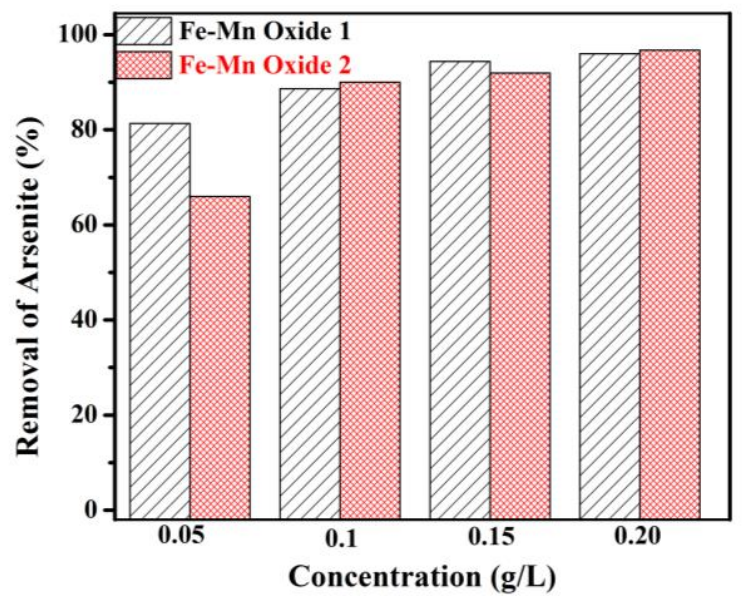

Figure: 6. Removal of As (III) with different concentration of adsorbents.

\section{CONCLUSION}

In this study, As (III) adsorption was studied under batch experiments as an adsorption kinetics, isotherms, and effect of $\mathrm{pH}$. Iron-Manganese oxides were prepared by oxidation and co-precipitation. Fe-Mn oxides were amorphous with many small aggregated particles which increases roughness of the adsorbents. Prepared adsorbents were highly efficient in the removal of As(III). $97 \%$ and $94 \%$ of As(III) was removed by Fe-Mn oxide-1 and Fe-Mn oxide- 2 respectively within 24 hours of reaction time. Pseudo-second order model describe well the adsorption mechanism $\left(\mathrm{R}^{2}=0.99\right)$. Adsorption decreases with increase in the $\mathrm{pH}$ value. $99 \%$ adsorption of $\mathrm{As}$ (III) was observed at $\mathrm{pH} 4.0$ by both oxides. 93\% and $89 \%$ adsorption of $\mathrm{As}$ (III) was observed at $\mathrm{pH} 9.0$ by Fe-Mn oxide-1 and Fe-Mn oxide- 2 respectively. Adsorption of As (III) increases with increase in the adsorbent dosage. Maximum adsorption was found at 0.2 $\mathrm{g} / \mathrm{L}$ adsorbent dose in both oxides. The Fe-Mn oxides system exhibits an obvious synergistic effect for the removal of As(III) in an aqueous solutions.

\section{ACKNOWLEDGEMENTS}

Authors are thankful to Environment and Climate study laboratory of Nepal Academy of Science and Technology 
(NAST) for providing laboratory facilities to carry out experiments. We are also grateful to Research Center for Eco-Environment Science (RCEES), Chinese Academy of Sciences (CAS), Beijing, China, for characterization of material by using SEM and XRD.

\section{REFERENCES}

1. Mohan, D., Pittman, C. U. Jr. 2007. Arsenic removal from water/wastewater using adsorbents--A critical review. Journal of Hazardous Materials. 142 (1-2): 1-53.

2. Mandal, B. K., Suzuki, K. T. 2002. Arsenic round the world: A review. Talanta. 58 (1): 201-235.

3. Jeon, C. S., Baek, K., Park, J. K., Oh, Y. K., Lee, S. D. 2009 Adsorption characteristics of $\mathrm{As}(\mathrm{V})$ on iron-coated zeolite Journal of Hazardous Materials. 163 (2-3): 804-8.

4. Qi, Z., Joshi, T. P., Liu, R., Li, Y., Liu, H., Qu, J. 2018 Adsorption combined with superconducting high gradient magnetic separation technique used for removal of arsenic and antimony. Journal of Hazardous Materials. 343: 36-48.

5. Goswami, A., Raul, P. K., Purkait, M. K. 2012.Arsenic adsorption using copper(II) oxide nanoparticles Chemical Engineering Research and Design. 90 (9): 1387-1396.

6. Goldberg, S., Johnston, C. T. 2001. Mechanisms of arsenic adsorption on amorphous oxides evaluated using macroscopic measurements, vibrational spectroscopy, and surface complexation modeling. Journal of Colloid and Interface Science. 234 (1): 204-216.

7. Joshi, T. P., Zhang, G., Jefferson, W. A., Perfilev, A. V., Liu, R., Liu, H., Qu, J. 2017. Adsorption of aromatic organoarsenic compounds by ferric and manganese binary oxide and description of the associated mechanism. Chemical Engineering Journal. 309: 577-587.

8. Gimenez, J., Martinez, M., de Pablo, J., Rovira, M., Duro, L. 2007. Arsenic sorption onto natural hematite, magnetite, and goethite. Journal of Hazardous Materials. 141 (3): 575-80.

9. Mertens, J., Rose, J., Kagi, R., Chaurand, P., Plotze, M., Wehrli, B., Furrer, G.2012. Adsorption of arsenic on polyaluminum granulates". Environmental Science \& Technology. 46 (13):73107317.
10. Liu, B., Jian, M., Liu, R., Yao, J., Zhang, X. 2015. Highly efficient removal of arsenic(III) from aqueous solution by zeoliticimidazolate frameworks with different morphology. Colloids and Surfaces A: Physicochemical and Engineering Aspects. 481: 358-366.

11. Jian, M., Liu, B., Zhang, G., Liu, R., Zhang, X.2015. Adsorptive removal of arsenic from aqueous solution by zeoliticimidazolate framework-8 (ZIF-8) nanoparticles. Colloids and Surfaces A: Physicochemical and Engineering Aspects. 465: 67-76.

12. Veličković, Z. S., Bajić, Z. J., Ristić, M. Đ., Djokić, V. R., Marinković, A. D., Uskoković, P. S., Vuruna, m. M. 2013. Modification of multi-wall carbon nanotubes for the removal of cadmium, lead and arsenic from wastewater. Digest Journal of Nanomaterials \& Biostructures. 8 (2): 501-511.

13. Zhao, Z., Jia, Y., Xu, L., Zhao, S. 2011. Adsorption and heterogeneous oxidation of $\mathrm{As}(\mathrm{III})$ on ferrihydrite. Water Research. 45 (19): 6496-504.

14. Raven, K. P., Jain, A., Loeppert, R. H. 1998. Arsenite and arsenate adsorption on ferrihydrite: kinetics, equilibrium, and adsorption envelopes. Environmental Science \& Technology. 32 (3): 344-349.

15. Dou, X., Mohan, D., Pittman, C. U., Jr. 2013. Arsenate adsorption on three types of granular schwertmannite. Water Research. 47 (9): 2938-48.

16. Zhang, G., Qu, J., Liu, H., Liu, R., Wu, R. 2007. Preparation and evaluation of a novel Fe-Mn binary oxide adsorbent for effective arsenite removal. Water Research. 41 (9): 1921-8.

17. Zhang, G., Liu, H., Liu, R., Qu, J. 2009. Removal of phosphate from water by a Fe-Mn binary oxide adsorbent. Journal of Colloid and Interface Science. 335 (2): 168-74.

18. Ho, Y. S. 2006. Second-order kinetic model for the sorption of cadmium onto tree fern: a comparison of linear and non-linear methods. Water Research. 40 (1): 119-25.

19. Ho, Y. S., Mckay, G. 1998. A Comparison of chemisorption kinetic models applied to pollutant removal on various sorbents. Process Safety \& Environmental Protection. 76: 332-340.

20. Joshi, T. P., Zhang, G., Cheng, H., Liu, R., Liu, H., Qu, J. 2017. Transformation of para arsanilic acid by manganese oxide: Adsorption, oxidation, and influencing factors. Water Research. 116: $126-134$

21. Chen, W. R., Huang, C. H. 2010. Adsorption and transformation of tetracycline antibiotics with aluminum oxide. Chemosphere. 79 (8): 779-85 